\title{
Associations of demographic variables and the Health Belief Model constructs with Pap smear screening among urban women in Botswana
}

This article was published in the following Dove Press journal: International Journal of Women's Health

23 October 2013

Number of times this article has been viewed

\section{Ditsapelo M McFarland}

College of Nursing and Public Health, Adelphi University, Garden City, NY, USA

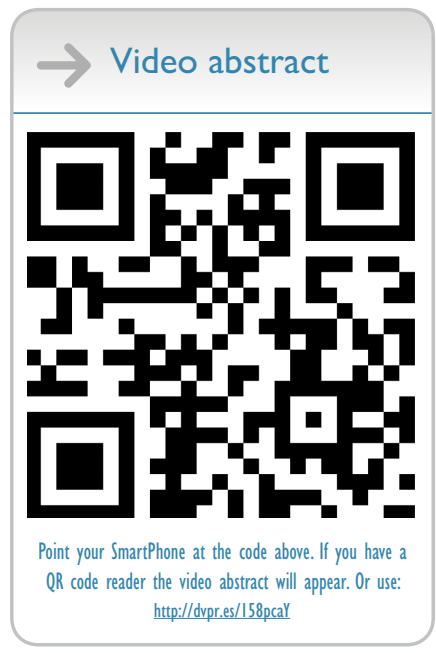

Correspondence: Ditsapelo M McFarland Adelphi University, One South Street, Garden City, NY I I530, USA

$\mathrm{Tel}+\mathrm{I} 5 \mathrm{I} 68774560$

Fax + I 5168774558

Email dmcfarland@adelphi.edu
Purpose: Papanicolaou (Pap) smear services are available in most urban areas in Botswana. Yet most women in such areas do not screen regularly for cancer of the cervix. The purpose of this article is to present findings on the associations of demographic variables and Health Belief Model constructs with Pap smear screening among urban women in Botswana.

Sample and methods: The study included a convenience sample of 353 asymptomatic women aged 30 years and older who were living in Gaborone, Botswana. Data were collected using a demographic questionnaire and items of the Health Belief Model. Data analysis included descriptive statistics for demographic variables and bivariate and ordinal (logit) regression to determine the associations of demographic variables.

Results: Having health insurance and having a regular health care provider were significant predictors of whether or not women had a Pap smear. Women with health insurance were more likely to have had a Pap smear test than women without health insurance ( $91 \%$ vs $36 \%$ ). Similarly, women who had a regular health care provider were more likely to have had a Pap smear test than women without a regular health care provider ( $94 \%$ vs $42 \%)$. Major barriers to screening included what was described as "laziness" for women who had ever had a Pap smear (57\%) and limited information about Pap smear screening for women who had never had a Pap smear (44\%).

Conclusion: There is a need for more information about the importance of the Pap smear test and for increased access to screening services in Botswana.

Keywords: cervical, screening, barriers, access, beliefs

\section{Introduction}

Cervical cancer is the second most common cancer among women worldwide, with approximately 500,000 new cases and 274,000 deaths each year. ${ }^{1}$ About $88 \%$ of the cases are in developing countries, accounting for $13 \%$ of all female cancers. The highest rates are found in South and Central America, sub-Saharan Africa (where Botswana is situated), and South and Southeast Asia. ${ }^{2,3}$ Cervical cancer is related to infection by Human papillomavirus (HPV) and is preventable. In developed countries, and in the United States in particular, the incidence of cervical cancer dramatically declined after the introduction of Papanicolaou (Pap) smear screening programs in the $1950 \mathrm{~s} .{ }^{4}$ In developing countries, Pap smear screening is not routinely done because of the lack of screening programs or because of their lack of effectiveness. ${ }^{5}$

In Botswana, however, Pap smear services are available for free in most urban areas. However, most women in these areas do not screen regularly for cancer of the cervix. Pap smear services are used largely for gynecological problems or as part of 
other services, such as family planning and maternal and child health, rather than for preventive purposes. ${ }^{6,7}$ As such, cervical cancer remains the most common cancer among women in Botswana. Cervical cancer accounted for $24 \%$ of all female cancers in Botswana between 1998 and 2008, 20\% of which were in women who were HIV-positive. It is estimated that every year, 163 women are diagnosed with cervical cancer and 83 die from the disease. Projections further suggest that by 2025 there will be 224 new cases of cervical cancer and 122 deaths from the disease. ${ }^{8}$ Such deaths can be prevented with regular Pap smear tests. Pap smear detects minor cervical lesions at an early stage, when they can be effectively treated and before they can advance to invasive carcinoma. ${ }^{9}$

In developed countries, demographic factors such as age, level of education, income, and ethnicity have been found to influence women's participation in cervical cancer screening. ${ }^{10-12}$ Furthermore, women who are not screened are predominantly from low-income backgrounds and are ethnic minorities. ${ }^{13}$ Personal beliefs are also important determinants of individual's participation in cervical cancer screening. ${ }^{14-16}$ In South Africa, researchers have concluded that attitudes and beliefs affect women's cervical cancer screening behavior. ${ }^{17}$ However, such factors have not been fully explored in Botswana.

Previous research in Botswana has found that Pap smear use was lower in women who had low incomes, low education, and no health insurance. Furthermore, the majority of the women perceived susceptibility to cervical cancer, its severity, and the benefits of the Pap smear tests. However, women who perceived more barriers to screening had fewer Pap smear tests compared with women who perceived fewer barriers. ${ }^{18}$ Other researchers in Botswana reported a low cervical cancer screening rate, at 39\%, and a significant association between perceived susceptibility and screening for cancer of the cervix. Women with high perceived susceptibility were more likely to screen for cancer of the cervix than those with low perceived susceptibility. ${ }^{19}$ Reports from another study indicated that nearly three-quarters of the women (72\%) had ever had a Pap smear, and factors such as age and income were associated with the likelihood of getting a Pap smear. ${ }^{20}$ In yet another study in Botswana, screening was more common among women who were older, had higher incomes, and had heard of cervical cancer. ${ }^{21}$ Researchers in other sub-Saharan countries reported similar findings. In Zimbabwe, for example, the women who were more likely to access cervical cancer screening were those who were financially independent compared with those who were financially dependent on their husbands. ${ }^{22}$
The purpose of this study is to present findings on the associations of demographic variables and concepts of the Health Belief Model with Pap smear use among urban women in Botswana. The data were generated as part of a larger, ongoing study designed to develop an instrument to measure beliefs about cervical cancer and Pap smear testing based on the Health Belief Model. The information obtained could assist health care providers develop interventions that are effective and accessible to the majority of the women.

The Health Belief Model was developed in the 1950s by Rosenstock and colleagues to explore reasons for low participation in preventive programs that were offered free of charge. ${ }^{23}$ The model states that an individual's decision to take a preventive measure against a particular condition is influenced by four beliefs: perceived susceptibility, perceived severity, perceived benefits, and perceived barriers. Perceived susceptibility refers to the individual's belief that he or she is at risk for contracting a particular disease or condition, such as cervical cancer. Perceived severity is the individual's belief in the seriousness of the disease in question if contracted or left untreated. Perceived benefits refer to the belief that engaging in a preventive action will lower the risk of contracting cervical cancer. Perceived barriers are those obstacles the individual believes deter them from taking preventive action. The model further asserts that for preventive action to take place, the benefits must outweigh the barriers. In addition to the four beliefs, cues or stimuli such as fear of the disease or illness symptoms (internal cues) and publicity or educational materials (external cues) are needed to trigger appropriate action. Furthermore, modifying factors can influence all other factors; they include demographic factors such as age, education, and ethnicity; sociopsychological factors such as social class and personality; and structural factors such as knowledge about the disease and prior experience with the disease. Age, social class, and personality have been cited frequently as being very influential in decisions regarding screening for cancer of the cervix. ${ }^{24}$

\section{Materials and methods}

A nonprobability convenience sampling was used to recruit asymptomatic women aged 30 years and older who were living in Gaborone, Botswana. Only black women of African descent were included in the study to avoid the influence of foreign belief systems. Because of the nature of the study, the sample selection was also limited to women who were able to complete an English questionnaire and who knew about the Pap smear test. Women with a history of hysterectomy (surgical removal of the womb) or cancer of the cervix were 
excluded from the study, as their responses might influence the study negatively.

Permission to conduct the study was obtained from relevant authorities in Botswana and participants before administration of the questionnaires. Women who met the inclusion criteria and chose to participate were given letters of informed consent to read and sign. The informed consent letters were written in English, as all participants were able read English. In the consent letter, participants were informed about the purpose of the study and that their participation was voluntary. Participants were also informed they could withdraw from the study at any time or refuse to answer certain questions if they so wished, with no adverse consequences. Participants were further informed they would not benefit directly by participating in the study and that they would not receive monetary incentive for their participation. Participants were also told there would be no harm associated with their participation in the study. Furthermore, participants were informed that the confidentiality of their responses would be assured through the use of numbers rather than their names to identify questionnaires, and that their responses would be reported as group rather than individual data.

Data from the participants included demographic items, Pap smear history, and an author-developed questionnaire based on the Health Belief Model. The demographic items included age, marital status, education, nature of employment, income, religion, and number of years participants had lived in the city. Items related to Pap smear determined whether the respondent had had a Pap smear, reasons for getting a Pap smear, the place where Pap smear was obtained, sources of information, number of Pap smears in the last 5 years, and what prevented the respondent from getting a Pap smear or the recommended number of Pap smears during the last 5 years.

The Health Belief Model items collected information on perceived susceptibility, perceived severity, perceived benefits, and perceived barriers. These items were generated from literature review and qualitative data. ${ }^{18}$ Initially, the health belief items were reviewed for relevance to the constructs by five faculty members who had expertise in women's health, instrument development, and the Health Belief Model. Content validity of the questionnaire was established by submitting the items to a panel of four experts who were advanced practice nurses of African descent and were familiar with the Health Belief Model. The content experts were asked to rate the content relevance of each item to the conceptually defined construct on a four-point Likert Scale ranging from 1 to 4 , where 1 represents not relevant, 2 is somewhat relevant, 3 is relevant, and 4 is very relevant, as suggested by Lynn. ${ }^{25}$ Cronbach's alpha of the scales ranged from 0.53 to 0.89 .

The questionnaire was pilot-tested on 20 asymptomatic Batswana women. Fifty-five belief items were measured on a 5-point Likert scale (from 1, strongly disagree, to 5, strongly agree). Data were collected with the help of four trained research assistants. The research assistants made efforts to recruit relevant women from various places and parts of the city for possible participation in the study, including work places and shopping malls. Recruitment was by word of mouth on contact, and the questionnaires were hand-delivered. Women who agreed to participate completed the questionnaires independently. The completed questionnaires were collected at the convenience of the participants and delivered as soon as possible to the researcher for safe keeping.

\section{Data analysis}

Four hundred questionnaires were distributed, and 368 were analyzed. Demographic and Pap smear history data were summarized descriptively, using SPSS software, version 16.0 (IBM Corporation, Armonk, NY, USA). Frequencies and percentages were calculated on all demographic and Pap smear items. Associations of demographic data and the Health Belief Model constructs with having had a Pap smear were determined through bivariate and ordinal (logit) regression analyses. Because of the very low frequency of participants aged 60 years or older $(n=2)$, this category was combined with the 50-59-year category and renamed $50+$ years. The small number of participants who were not sure whether they had ever had a Pap smear $(n=15 ; 4 \%)$ were excluded from the analysis because of the nature of the survey, which asked about perceptions about Pap smears. As would be expected, this group also had a higher frequency of a "not sure" or no response to survey items. The two small categories of marital status (divorced or separated, $n=30$; widowed, $n=18$ ) were combined.

\section{Results Demographic variables}

Ninety percent of the participants were between 30 and 49 years of age, with just under half (46\%) married and more than three-quarters $(77 \%)$ having greater than secondary education. The vast majority were employed (92\%) and in the service delivery sector (42\%). Just more than three-quarters had health care insurance (76\%), and 69\% 
had a regular health care provider, with the majority (69\%) having a physician as their regular health care provider. Each of the four categories of religion was well represented ( $\geq 19 \%$ ). A clear majority (69\%) had lived in Gaborone for between 6 and 20 years. Demographic variable distributions are displayed in Table 1.

\section{Pap smear practices}

Just over three-quarters (77\%) of the respondents had ever had a Pap smear, with half (50\%) of those having asked for this test to be included in their regular checkups. Two thirds (67\%) had their Pap smear at a private doctor's office, with $62 \%$ having heard about it from their health care providers. The rest of the participants $(33 \%)$ had a Pap smear either at a clinic or a hospital. Just more than half of the participants $(52 \%)$ had one to two Pap smears in the last 5 years. Only $18 \%$ had the recommended four or five Pap smears during the last 5 years, and the majority attributed this to "laziness." Those women who had never had a Pap smear cited lack of information $(44 \%)$ or financial constraints $(31 \%)$ as their barriers to screening. These findings are summarized in Table 2.

Table I Sample demographics results $(n=368)$

\begin{tabular}{|c|c|c|}
\hline Characteristic & Frequency & $\%$ \\
\hline \multicolumn{3}{|l|}{ Age in years (no response $=12$ ) } \\
\hline $30-39$ & 206 & 58 \\
\hline $40-49$ & 115 & 32 \\
\hline $50+$ & 35 & 10 \\
\hline \multicolumn{3}{|l|}{ Marital status (no response $=5$ ) } \\
\hline Single/never married & 145 & 40 \\
\hline Married & 167 & 46 \\
\hline Divorced/separated/widowed & 51 & 14 \\
\hline \multicolumn{3}{|l|}{ Education (no response $=6$ ) } \\
\hline Primary & 21 & 6 \\
\hline Secondary & 63 & 17 \\
\hline Vocational & $|4|$ & 39 \\
\hline University degree & 137 & 38 \\
\hline \multicolumn{3}{|c|}{ Nature of employment (no response $=10$ ) } \\
\hline Clerical & 73 & 22 \\
\hline Teaching & 54 & 17 \\
\hline Management & 61 & 19 \\
\hline Service delivery & 136 & 42 \\
\hline \multicolumn{3}{|c|}{ Monthly income (no response $=32$ ) } \\
\hline$<\mathrm{P} 5,000(\$ 833)$ & 87 & 26 \\
\hline P5,000-P9,999 & 183 & 55 \\
\hline PI0,000-PI4,999 & 48 & 14 \\
\hline PI5,000+ $(\$ 2,500)$ & 18 & 5 \\
\hline \multicolumn{3}{|l|}{ Religion $($ no response $=19$ ) } \\
\hline Catholic & 125 & 36 \\
\hline Protestant & 67 & 19 \\
\hline Faith healing & 90 & 26 \\
\hline None & 67 & 19 \\
\hline
\end{tabular}

Notes: Monthly income is given in Pula (P), the currency in Botswana. \$ are USD.
Table 2 Pap smear practices $(\mathrm{n}=353)$

\begin{tabular}{|c|c|c|}
\hline Characteristics & $\mathbf{n}$ & $\%$ \\
\hline \multicolumn{3}{|l|}{ Ever had a Pap smear (not sure $=15$ ) } \\
\hline No & 80 & 23 \\
\hline Yes & 273 & 77 \\
\hline \multicolumn{3}{|c|}{ Reasons for getting a Pap smear (no response $=17$ ) } \\
\hline Asked at check-up & 128 & 50 \\
\hline Had uterus problems & 65 & 25 \\
\hline Part of service & 62 & 25 \\
\hline HIV status & 1 & $<1$ \\
\hline \multicolumn{3}{|c|}{ Place where Pap smear was done (no response $=18$ ) } \\
\hline Private doctor's office & 170 & 67 \\
\hline Clinic & 39 & 15 \\
\hline Hospital & 46 & 18 \\
\hline \multicolumn{3}{|l|}{ Sources of Information (no response $=16$ ) } \\
\hline Health care provider & 160 & 62 \\
\hline Mass media & 66 & 26 \\
\hline Family/friends & 31 & 12 \\
\hline \multicolumn{3}{|c|}{ Number of Pap smears in the past five years (no response $=3$ ) } \\
\hline None & 19 & 7 \\
\hline One or two & $|4|$ & 52 \\
\hline Three & 62 & 23 \\
\hline Four or five & 48 & 18 \\
\hline \multicolumn{3}{|c|}{ Reasons for getting fewer Pap smears in the past 5 years (no response $=2$ ) } \\
\hline Laziness & 126 & 57 \\
\hline Pap smear not seen as important & 43 & 19 \\
\hline Negative attitude of Pap smear provider & 23 & 10 \\
\hline Financial constraints & 32 & 14 \\
\hline \multicolumn{3}{|c|}{ Reasons for never getting a Pap smear (no response $=16$ ) } \\
\hline Limited information & 28 & 44 \\
\hline Limited access & 12 & 19 \\
\hline Negative attitude of providers & 4 & 6 \\
\hline Financial constraints & 20 & 31 \\
\hline
\end{tabular}

Abbreviation: Pap, Papanicolaou.

\section{Associations of demographic variables}

Bivariate analysis explored the associations of demographic variables, using $P=0.01$ as the significance level to partially compensate for multiplicity. Older women more often had health care insurance $(P=0.001)$ and a regular health care provider $(P=0.002)$ and were more frequently divorced, separated, or widowed $(P<0.0005)$. Level of education was highly associated with employment status $(P<0.0005)$, income $(P<0.0005)$, having health care insurance $(P<0.0005)$, and having a regular health care provider but was not associated with marital status $(P=0.02)$. Employment status was associated with having health care insurance $(P<0.0005)$ and having a regular health care provider $(P<0.0005)$, and more single women were not employed $(P=0.004)$. Religion was not associated with age, education, employment status, monthly income, or marital status, but women who chose faith healing or none for religion were less likely to have health care insurance or a regular health care provider $(P=0.007)$. 


\section{Associations of demographic variables with ever or never had Pap smear}

Because of the significant associations between demographic variables, ordinal regression (logit) was conducted for those variables that demonstrated significant association with ever having a Pap smear. There was no significant relationship among age, marital status, level of education, employment, income, religion, and Pap smear testing. Only two variables were significant predictors of whether or not a participant had ever had a Pap smear: having health care insurance $(P \leq 0.0005)$ and having a health care provider $(P \leq 0.0005)$. Women with health insurance (Medical Aid) were more likely than those without health insurance to have had a Pap smear test (91\% vs 36\%). Similarly, women who had a regular health care provider were more likely than those without a regular health care provider to have ever screened for cancer of the cervix ( $94 \%$ vs $42 \%$ ). These results are displayed in Table 3.

\section{Sources of information and number of Pap smears in the last 5 years}

In the data, there was a significant association between where women heard about Pap smears and their number of smears in the last 5 years $(P<0.0005)$. Women who never had a Pap $(n=80)$ stated they get their information from the mass media mostly, and then family/friends. Women who had ever had a Pap were informed mainly by their health care provider and then the mass media. These findings are summarized in Figure 1.

\section{Associations of the Health Belief Model components with ever or never had a Pap smear}

To analyze the associations of different dimensions of the Health Belief Model, the component scores were averaged as constructed using the factor analysis solutions ( 1 , strongly disagree; 2 , disagree; 3 , neutral; 4 , agree; and 5 , strongly agree). Women strongly perceived the benefits of getting Pap smears and the severity of cervical cancer. The averaged responses to both perceived severity and perceived benefits were greater than the averaged responses of perceived susceptibility and perceived barriers. There was no significant relationship between Pap smear screening and components of the Health Belief Model. Women who had ever had a Pap smear and women who had never had a Pap smear were very similar with respect to beliefs of the Health Belief Model. Profiles of responses for both groups were very similar. This information is displayed in Figure 2. Table 4 shows no
Table 3 Demographic variables and never or ever had a Papanicolaou (Pap) smear

\begin{tabular}{|c|c|c|c|}
\hline Characteristic & $\begin{array}{l}\text { Ever had a } \\
\text { Pap smear }\end{array}$ & $\begin{array}{l}\text { Never had a } \\
\text { Pap smear }\end{array}$ & $P$-value \\
\hline \multicolumn{4}{|c|}{ Age in years (no response $=12$ ) } \\
\hline $30-39$ & 148 (75\%) & $50(25 \%)$ & 0.160 \\
\hline $40-49$ & $94(84 \%)$ & $18(16 \%)$ & \\
\hline $50+$ & $25(81 \%)$ & $6(19 \%)$ & \\
\hline \multicolumn{4}{|c|}{ Marital status (no response $=5$ ) } \\
\hline Single & $95(70 \%)$ & $4 \mathrm{I}(30 \%)$ & 0.003 \\
\hline Married & $140(86 \%)$ & $23(14 \%)$ & \\
\hline $\begin{array}{l}\text { Divorced/separated/ } \\
\text { widowed }\end{array}$ & 37 (75\%) & $37(25 \%)$ & \\
\hline \multicolumn{4}{|c|}{ Highest level of education (no response $=6$ ) } \\
\hline Primary & $7(4 \mid \%)$ & $10(59 \%)$ & $<0.0005$ \\
\hline Secondary & $38(62 \%)$ & $23(38 \%)$ & \\
\hline Vocational & $110(83 \%)$ & $23(17 \%)$ & \\
\hline University & $117(86 \%)$ & $19(14 \%)$ & \\
\hline \multicolumn{4}{|c|}{ Employment (no response $=6$ ) } \\
\hline No & $6(24 \%)$ & $19(76 \%)$ & $<0.0005$ \\
\hline Yes & $266(83 \%)$ & $56(17 \%)$ & \\
\hline \multicolumn{4}{|c|}{ Monthly income (no response $=32$ ) } \\
\hline$<\mathrm{P} 5,000$ & $52(66 \%)$ & 27 (34\%) & $<0.0005$ \\
\hline P5,000-P9,999 & $153(85 \%)$ & 27 (I5\%) & \\
\hline PI0,000-PI4,999 & $43(91 \%)$ & $4(9 \%)$ & \\
\hline PI5,000 and above & $18(100 \%)$ & & \\
\hline \multicolumn{4}{|c|}{ Health/medical insurance (no response $=7$ ) } \\
\hline No & $28(36 \%)$ & $50(64 \%)$ & $<0.0005$ \\
\hline Yes & $245(91 \%)$ & $24(9 \%)$ & \\
\hline \multicolumn{4}{|c|}{ Regular health care provider (no response $=\mathrm{II}$ ) } \\
\hline No & $4 \mathrm{I}(42 \%)$ & $57(58 \%)$ & $<0.0005$ \\
\hline Yes & 231 (94\%) & $14(6 \%)$ & \\
\hline \multicolumn{4}{|c|}{ Religion (no response $=19$ ) } \\
\hline Catholic & $100(84 \%)$ & $19(16 \%)$ & 0.005 \\
\hline Protestant & 57 (90\%) & $6(10 \%)$ & \\
\hline Faith healing & $59(69 \%)$ & 26 (31\%) & \\
\hline None & $49(3 \%)$ & 18 (27\%) & \\
\hline
\end{tabular}

Notes: Significance level set at 0.006 (Bonferroni correction for nine tests). Monthly income is given in Pula (P), the currency in Botswana.

significant differences between yes and no responses to getting Pap smear and beliefs of the Health Belief Model. The means and standard deviations are very similar for both groups.

\section{Discussion}

Having health insurance and having a regular health care provider were the only two variables significantly associated with getting a Pap smear test. Women with medical insurance were more likely to have had a Pap smear test than women without medical insurance, yet only a few of them had four to five Pap smears in the last 5 years, largely because of what the women described as "laziness." Similarly, women who had a regular health care provider were more likely to have had a Pap smear test than women without a regular health care provider. These findings are consistent with those of an 


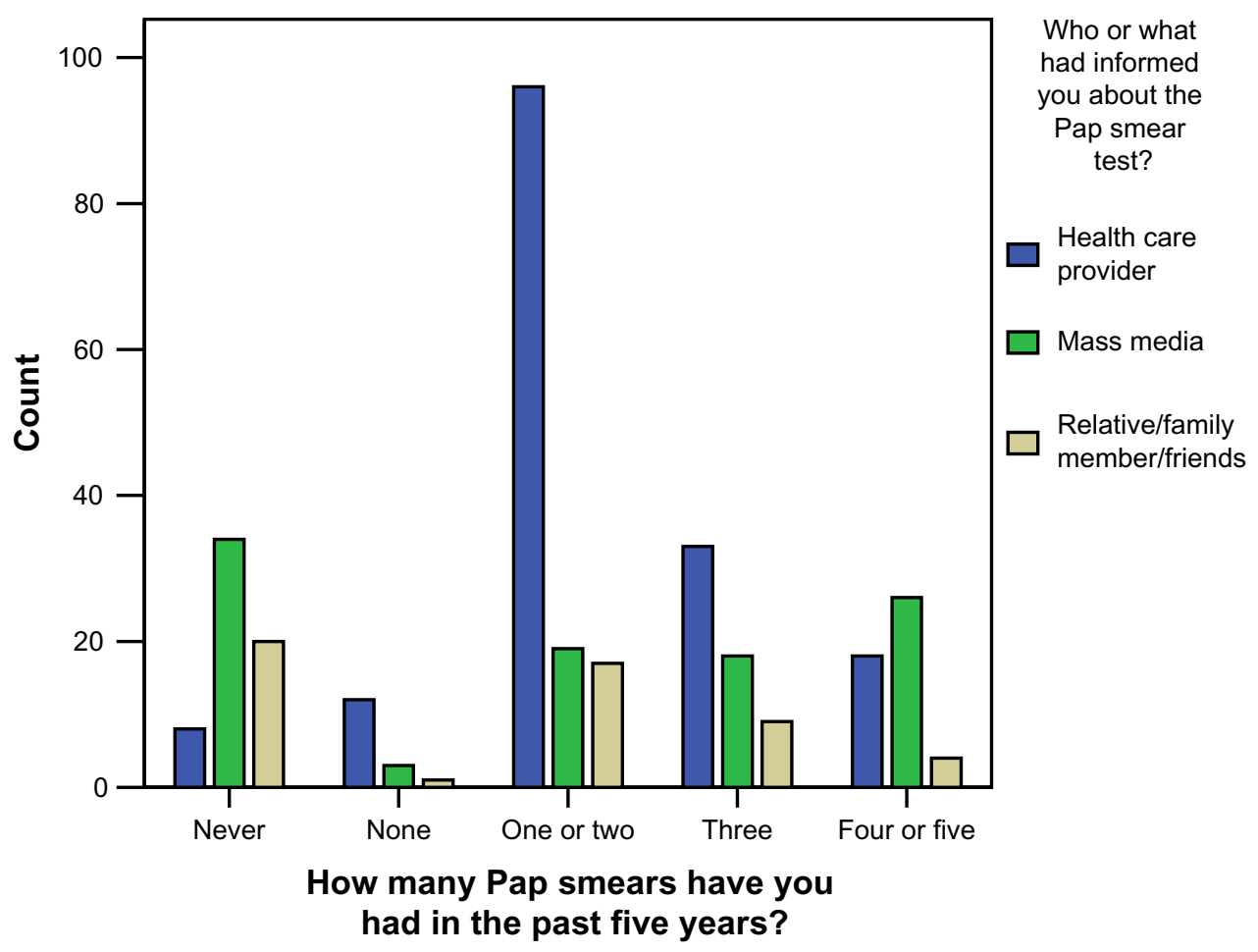

Figure I Sources of information and number of Papanicolaou (Pap) smears in the past 5 years $(n=353)$.

earlier study by McFarland. ${ }^{18}$ In that study, the majority of the women had medical insurance and received their Pap smear tests from private practitioners, who reportedly informed them about the importance of early detection. However, only a few of the respondents had regular Pap smear tests.
Similarly, women with access to sources of information cited "laziness" or lack of motivation as their major barrier to regular Pap smear screening. The majority of the women received Pap smear tests from private physicians and were informed about Pap smear testing by their health

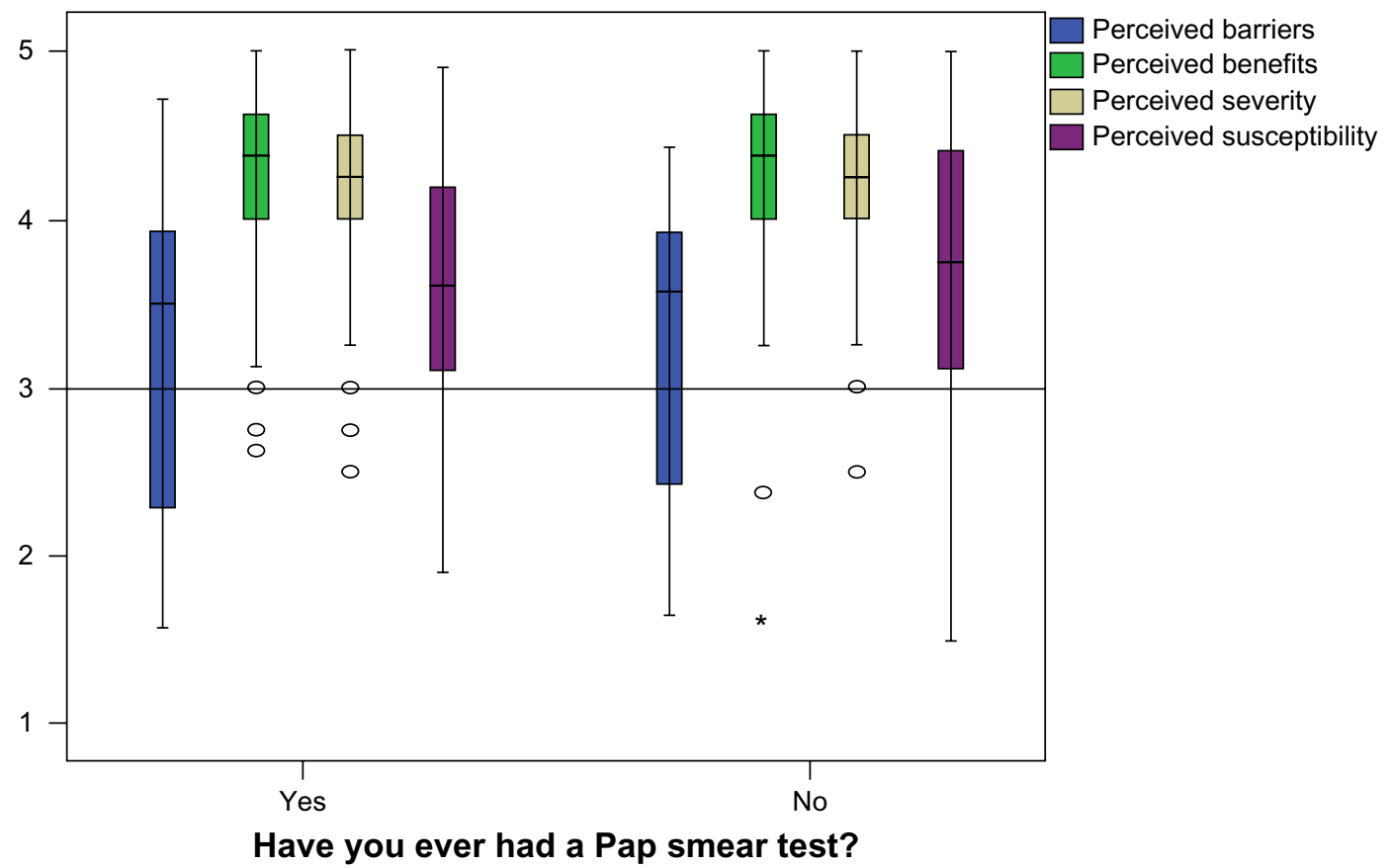

Figure 2 Box plot of association of smear use with the Health Belief Model variables $(n=353)$.

Note: The circles shown in the graph represent outliers and the star represents an extreme value. 
Table 4 Means and standard deviations of the health beliefs and never or ever had Pap smear $(n=353)$

\begin{tabular}{lllll}
\hline Beliefs & $\begin{array}{l}\text { Ever had } \\
\text { Papanicolaou } \\
\text { smear? }\end{array}$ & n & Mean & $\begin{array}{l}\text { Standard } \\
\text { deviation }\end{array}$ \\
\hline Perceived & Yes & 273 & 3.3 & 0.79 \\
susceptibility & No & 80 & 3.4 & 0.88 \\
Perceived & Yes & 273 & 3.7 & 0.36 \\
severity & No & 80 & 3.8 & 0.47 \\
Perceived & Yes & 273 & 4.1 & 0.47 \\
benefits & No & 80 & 4.2 & 0.42 \\
Perceived & Yes & 273 & 3.2 & 0.43 \\
barriers & No & 80 & 3.3 & 0.49
\end{tabular}

Note: Women perceived severity and benefits.

Abbreviation: Pap, Papanicolaou.

care providers. Furthermore, mass media played a significant role in informing these women who had ever had a Pap smear. It is also indicated that these women considered Pap smear not as important to them

These findings clearly suggest that attitudes toward screening were major factors in women's failure to screen for cervical cancer regularly. Another explanation for low use of the available Pap smear services could be that preventive health using Pap smears is a foreign concept that people in Botswana do not understand and are still grappling with. It could also be that Batswana tend to seek health care only when they have disease symptoms. These concerns have been cited by authors in other sub-Saharan countries. ${ }^{26,27}$

Women who had never had a Pap smear mentioned a lack of information about Pap smear testing and financial constraints as their major barriers to Pap smear screening. This could be because women who have no insurance and a regular health care provider tend to receive most of their health care from the clinics in which Pap smear is not accessible on a regular basis. It could also be that because of a lack of health insurance, the women who had never screened are not able to access private practitioners for health services. As indicated, sources of information for these women who had never had a Pap smear are family and friends, who also may not be well-informed about Pap smear screening.

Older and married women were more likely than younger and single women to have been screened. Perhaps older and married women have more resources to access sources of information compared with younger and unmarried women. These findings are similar to other studies done in Botswana. In addition, women aged 31 years old or older were more likely to have had a Pap smear, as were those who earned a regular income. ${ }^{20}$
Women who had higher levels of education were more likely than women with lower levels of education to have had a Pap smear, and other researchers in Botswana have reported similar findings. ${ }^{18-22}$

Women with no religion or who belonged to the faith healing churches were less likely than women of other religious affiliations to have had a personal health care provider or to have been screened for cancer of the cervix. Perhaps these women hold beliefs about preventive health care that are different from those of other women, suggesting the need for further exploration of such belief systems as they relate to taking a preventive action against cervical cancer.

There were no significant associations between concepts of the Health Belief Model and whether or not a woman had a Pap smear. Women in this study perceived the severity of cervical cancer and benefits of the Pap smear tests, yet few had the recommended tests. Conversely, respondents perceived lower susceptibility to cervical cancer. This could mean that women do not know what puts them at risk for cervical cancer. These findings are inconsistent with earlier findings, ${ }^{18,19}$ in which case, respondents were aware of their perceived susceptibility to cervical cancer. Respondents also perceived fewer barriers to obtaining Pap smear tests. However, the study identified "laziness" as a major barrier for women who ever had Pap smear test and lack of information about Pap smear testing for women who had never had a Pap smear test.

There were no significant relationships between all demographic variables and components of the Health Belief Model constructs in this sample of mostly long-term residents of Gaborone. The overall pattern seen in one graph was generally repeated for all demographic variables; for example, for all ages, the pattern was the same with no real differences. There were also no significant differences between yes/no as to whether or not the respondent ever had a Pap smear and components of the Health Belief Model, which was not expected. This could be explained by limited knowledge about cervical cancer and importance of the Pap smear in detecting it.

\section{Conclusion}

The author concludes that women in this study are informed about cancer of the cervix and have access to screening. However, attitudes toward screening play a major role as a barrier to screening for women who had ever screened. These attitudes were evidenced by the women reporting "laziness" as a major reason why they did not screen regularly. In light of the high incidence of HIV/AIDS in Botswana, these attitudes toward Pap smear use could significantly contribute 
to an increase in the incidence of cervical cancer, and they suggest a need to be further explored. The study was limited in several ways. The study used women identified by convenience sampling, which could raise an issue of potential sampling bias. Furthermore, the data were collected through a self-reporting approach. As such, the findings could have been affected by a social desirability response. Further studies are needed to identify limited use of the available Pap smear services, using probability sampling and instruments that are reliable and valid.

\section{Acknowledgments}

The author thanks the University of Botswana for financial support to undertake the study, Professor Sarah Gueldner of Case Western Reserve University, Ohio, USA, and Dr Jane White of the Adelphi University, Garden City, NY, USA, for their valuable contributions, and DrYvonne Michel of Medical University of South Carolina, Charleston, South Carolina, USA, for statistical assistance. Many thanks also go to Dove Medical Press for reviewing the manuscript before its resubmission.

\section{Disclosure}

The author reports no conflicts of interest in this work.

\section{References}

1. World Health Organization. Cervical cancer, human papillomavirus (HPV) and HPV vaccines: Key points for policy-makers and health professionals. World Health Organization; 2008. Available from: http://whqlibdoc.who. int/hq/2008/WHO_RHR_08.14_eng.pdf. Accessed April 4, 2013.

2. Ferlay J, Shin HR, Bray F, Forman D, Mathers C, Parkin DM. Estimates of worldwide burden of cancer in 2008: GLOBOCAN 2008. Int J Cancer. 2010;127(12):2893-2917. doi: 10.1002/ijc.25516

3. International Agency on Research for Cancer. GLOBOCAN 2008. Estimated cancer Incidence, Mortality, Prevalence and Disabilityadjusted life years (DALYs) Worldwide in 2008. Available from: http:// globocan.iarc.fr/. Accessed April 4, 2013.

4. National Cancer Institute. SEER Cancer Statistics Review, 1975-2006. Available from: http://seer.cancer.gov/csr/1975_2006/. Accessed April 4, 2013.

5. Sankaranarayanan R, Budukh AM, Rajkumar R. Effective screening programmes for cervical cancer in low- and middle-income developing countries. Bull World Health Organ. 2007;9(10):954-962. Epub November 1, 2001.

6. Central Statistics Office (2009). Health Statistics Report 2006. Department of Printing and Publishing Services: Gaborone, Botswana.

7. Botswana National Cancer Registry (2007) Analysis of Registered Cancer Patients 1986-2006. Department of Public Health Disease Control Unit: Gaborone, Botswana.

International Journal of Women's Health

\section{Publish your work in this journal}

The International Journal of Women's Health is an international, peerreviewed open-access journal publishing original research, reports, editorials, reviews and commentaries on all aspects of women's healthcare including gynecology, obstetrics, and breast cancer. The manuscript management system is completely online and includes

Submit your manuscript here: http://www.dovepress.com/international-journal-of-womens-health-journal
8. World Health Organization/Institut Català d'Oncologia (September 15, 2010). Human papillomavirus and related cancers in Botswana. A summary report Update. Available from: http://www.hpvcentre.net/statistics/ reports/BWA.pdf. Accessed May 14, 2013.

9. Young EQ, Davis MS. Women's Health: A Primary Care Clinical Guide. 3rd ed. Upper Saddle River, NJ: Pearson Prentice Hall; 2004.

10. Calle EE, Flanders WD, Thun MJ, Martin LM. Demographic predictors of mammography and Pap smear screening in US women. Am J Public Health. 1993;83(1):53-60.

11. Yi JK. Factors associated with cervical cancer screening behavior among Vietnamese women. J Community Health. 1994;19(3):189-200.

12. Yu MY, Seetoo AD, Tsai CK, Sun C. Sociodemographic predictors of Papanicolaou smear test and mammography use among women of Chinese descent in southeastern Michigan. Womens Health Issues. Dec 1998;8(6):372-381.

13. Harlan LC, Bernstein AB, Kessler LG. Cervical cancer screening: who is not screened and why? Am J Public Health. 1991;81(7):885-890.

14. Lee EE, Fogg L, Menon U. Knowledge and beliefs related to cervical cancer and screening among Korean American women. West $J$ Nurs Res. 2008;30(8):960-974. doi: 10.1177/0193945908319250. Epub June 6, 2008.

15. McMullin JM, De Alba I, Chávez LR, Hubbell FA. Influence of beliefs about cervical cancer etiology on Pap smear use among Latina immigrants. Ethn Health. 2005;10(1):3-18.

16. Womeodu RJ, Bailey JE. Barriers to cancer screening. Med Clin North Am. 1996;80(1):115-133.

17. Mosavel M, Simon C, Oakar C, Meyer S. Cervical cancer attitudes and beliefs-a Cape Town community responds on World Cancer Day. JCancer Educ. 2002;4(2):114-119. doi: 10.1080/08858190902854590

18. McFarland DM. Cervical cancer and Pap smear screening in Botswana: knowledge and perceptions. Int Nurs Rev. 2003;50(3):167-175.

19. Ibekwe CM, Hoque ME, Ntuli-Ngcobo B. Perceived benefits of cervical cancer screening among women attending Mahalapye district hospital, Botswana. Asian Pacific J Cancer Prev. 2010;11:1021-1027.

20. DiAngi TY. Cervical cancer screening accepted in Botswana. Available from: http://www.health24.com/Medical/Cervical-cancer/News/ Cervical-cancer-screening-accepted-in-Botswana-20120721. Accessed March 5, 2012.

21. Mingo AM, Panozzo CA, DiAngi YT, et al. Cervical cancer awareness and screening in Botswana. Int J Gynecol Cancer. 2012;22(4):638-644. doi: 10.1097/IGC.0b013e318249470a

22. Mupepi SC, Sampselle CM, Johnson TR. Knowledge, attitudes, and demographic factors influencing cervical cancer screening behavior of Zimbabwean women. JWomens Health (Larchmt). 2011;20(6):943-952. doi: $10.1089 /$ jwh.2010.2062

23. Rosenstock IM. Historical origins of the health belief model. Health Education Monographs. 1974;24:238-335.

24. Gillam SJ. Understanding the uptake of cervical cancer screening: the contribution of the health belief model. Br J Gen Pract. 1991;41(353): 510-513.

25. Lynn MR. Determination and quantification of content validity. Nurs Res. Dec 1986;35(6):382-385.

26. Frost O. Some aspects of the problem of carcinoma of the cervix in Zimbabwe. Cent Afr J Med. 1981;27(9):169-171.

27. Chikunogwa E, Borok MZ, Nyakabau AM. Patterns of cancer in Zimbabwe. National Cancer Registry Annual Report; 2003.

a very quick and fair peer-review system, which is all easy to use. Visit http://www.dovepress.com/testimonials.php to read real quotes from published authors. 